\title{
I Will Know
}

\section{Candy McCormic, Cathy Muñoz}

\section{Will Know}

Although we have never met I have always thought of you and with that said...

I know you more than myself.

I have replayed the sound of your voice many times.

I know it sounds absurd but it soothes my mind.

And you do not realize this yet but our hands fit just right.

And we don't have to say a word when we kiss goodnight.

Then there is that grin it matches your smiling eyes.

And I smile right back at you and cry...

Because you know, love does that to you.

It tears at your heart strings and you would not trade that feeling for anything. 
So I will wait forever

for that day when we meet.

Perhaps in a café or on a busy street.

In a book store reading poetry

by Robert Frost

and you thumbing through travel books

looking fairly lost.

I will know.

I will know that finally

those eyes I have only dreamed about

will gaze into mine

and it's time...

Time to let go.

I do not have to miss you anymore

because now I have you.

And well, that was what my forever was for... 


\section{Yo lo sabré}

Aunque nunca nos hemos conocido

siempre he pensado en ti

y con eso dicho...

Te conozco más que a mí misma

he reproducido el sonido de tu voz

muchas veces.

Sé que suena absurdo

pero calma mi mente.

Y no te das cuenta de esto todavía

pero nuestras manos encajan perfectamente.

$Y$ no tenemos que decir ninguna palabra

cuando nos damos el beso de buenas noches.

Luego está esa sonrisa

que corresponde a tus ojos sonrientes.

Y te devuelvo la sonrisa

y 1loro...

Porque, sabes, el amor te provoca eso.

Te conmueve el corazón

y no cambiarías ese sentimiento

por nada.

Yo esperaré eternamente

ese día en que nos encontremos.

Tal vez en una cafetería o en una calle muy transitada.

En una librería leyendo poesía

de Robert Frost

y tú hojeando libros de viaje

como ausente.

Yo lo sabré.

Yo sabré que finalmente 
esos ojos que he soñado

verán los míos

y será hora...

Hora de dejarlo ir.

Ya no tengo que extrañarte más

porque ahora te tengo.

Y bueno, para eso habrá sido mi siempre jamás... 